\title{
Climate Variability and Malaria over West Africa
}

\begin{abstract}
Ibrahima Diouf, ${ }^{1,2 \star}$ Belén Rodriguez Fonseca, ${ }^{3,4}$ Cyril Caminade, ${ }^{5,6}$ Wassila M. Thiaw, ${ }^{1}$ Abdoulaye Deme, ${ }^{7}$ Andrew P. Morse, ${ }^{6,8}$ Jacques-André Ndione, ${ }^{9}$ Amadou Thierno Gaye, ${ }^{2}$ Anta Diaw, ${ }^{10}$ and Marie Khemesse Ngom Ndiaye ${ }^{10}$

${ }^{1}$ NOAA Center for Weather and Climate Prediction, College Park, Maryland; ' 2 Laboratoire de Physique de L'Atmosphère et de L'Océan-Siméon Fongang, Ecole Supérieure Polytechnique de L'Université Cheikh Anta Diop, Dakar, Sénégal; ${ }^{3}$ Department of Geophysics and Meteorology, Universidad Complutense de Madrid, Madrid, Spain; ${ }^{4}$ Instituto de Geociencias IGEO, CSIC-UCM, Agencia Estatal del Consejo Superior de Investigaciones Cientificas, Madrid, Spain; ${ }^{5}$ Department of Epidemiology and Population Health, Institute of Infection and Global Health, University of Liverpool, Liverpool, United Kingdom; ${ }^{6}$ National Institute for Health Research [M1] (NIHR), Health Protection Research Unit in Emerging and Zoonotic Infections, Liverpool, United Kingdom; ${ }^{7}$ Unité de Formation et de Recherche de Sciences Appliquées et de Technologie, Université Gaston Berger, Saint Louis, Sénégal; ${ }^{8}$ Department of Geography and Planning, School of Environmental Sciences, University of Liverpool, Liverpool, United Kingdom; ${ }^{9}$ Centre de Suivi Écologique, Dakar, Sénégal; ${ }^{10}$ General Direction of Public Health, Ministry of Health and Social Action, Dakar, Senegal
\end{abstract}

\begin{abstract}
Malaria is a major public health problem in West Africa. Previous studies have shown that climate variability significantly affects malaria transmission. The lack of continuous observed weather station data and the absence of surveillance data for malaria over long periods have led to the use of reanalysis data to drive malaria models. In this study, we use the Liverpool Malaria Model (LMM) to simulate spatiotemporal variability of malaria in West Africa using daily rainfall and temperature from the following: Twentieth Century Reanalysis (20th CR), National Center for Environmental Prediction (NCEP), European Centre for Medium-Range Weather Forecasts (ECMWF) Atmospheric Reanalysis of the Twentieth Century (ERA20C), and interim ECMWF Re-Analysis (ERA-Interim). Malaria case data from the national surveillance program in Senegal are used for model validation between 2001 and 2016. The warm temperatures found over the Sahelian fringe of West Africa can lead to high malaria transmission during wet years. The rainfall season peaks in July to September over West Africa and Senegal, and the malaria season lasts from September to November, about 1-2 months after the rainfall peak. The long-term trends exhibit interannual and decadal variabilities. The LMM shows acceptable performance in simulating the spatial distribution of malaria incidence. However, some discrepancies are found. These results are useful for decision-makers who plan public health and control measures in affected West African countries. The study would have substantial implications for directing malaria surveillance activities and health policy. In addition, this malaria modeling framework could lead to the development of an early warning system for malaria in West Africa.
\end{abstract}

\section{INTRODUCTION}

Malaria is a climate-sensitive vector-borne disease. Presently, $90 \%$ of malaria deaths are reported in Africa, and the largest outbreaks tend to occur in sub-Saharan Africa. ${ }^{1-5}$ In Senegal, malaria represents more than $5 \%$ of consultations in health services, with a mortality rate of about $7 \% .{ }^{6,7}$ Interactions among the mosquito vector, the Plasmodium parasite, and the human host are conditioned by suitable climate conditions. Although climate is not the leading driver affecting the geographic distribution and epidemiology of malaria, ${ }^{8-11}$ it influences malaria through different pathways. Temperature influences the development and mortality of the Anopheles vectors and their biting rates. ${ }^{12}$ Rainfall creates breeding sites for the larval stage of the mosquito vector development. ${ }^{13-15}$ In addition, higher temperatures, especially in the $18-32^{\circ} \mathrm{C}$ range, tend to increase malaria transmission as it accelerates the life cycle of Anopheles vectors (gonotrophic cycle, i.e., egg laying frequency and their development rate) and reduces the length of the sporogonic cycle inside female Anopheles mosquitoes. As an example, the common form of the tropical parasite, Plasmodium falciparum, has an $18^{\circ} \mathrm{C}$ minimum threshold to develop in the vector. ${ }^{16,17}$ To a lesser extent, humidity is an important parameter that influences malaria transmission as well. Humidity equal or greater than $60 \%$ increases mosquito survival. ${ }^{18}$ The frequency and intensity of precipitation are

*Address correspondence to Ibrahima Diouf, NOAA Center for Weather and Climate Prediction, 5830 University Research Court, College Park, MD 20740. E-mail: ibrahima.diouf@noaa.gov crucial factors that create breeding sites for mosquitoes, and, consequently, modulate peaks in vector abundance. ${ }^{19}$ The seasonal transmission risk of malaria is modulated by seasonal rainfall, related to monsoon systems in the Tropics. ${ }^{20}$ Years with heavy rainfall are often related to larger-than-average malaria burden; for example, floods can hamper vector control measures in place by destroying health infrastructures in the region. ${ }^{21}$ However, excessive rainfall can also flush mosquito larvae sites, leading to decreased malaria risk. ${ }^{22}$ In addition, some Anopheles mosquitoes prefer clear or shaded water, whereas others prefer brackish or salty water. ${ }^{23-26}$ Therefore, consequently, climate change might alter the global distribution of malaria in the future. ${ }^{27}$ The severe drought that took place over the Sahel during the 1970 s and $1980 s^{28-30}$ led to a reduction in the distribution and abundance of Anopheles vectors, ${ }^{31,32}$ but, surprisingly, the associated reduction of mosquito vectors did not necessarily lead to a drastic reduction in malaria cases and deaths. The growing resistance of mosquito vectors to insecticides, which are commonly used in insecticide-treated bed nets (ITNs) and indoor residual spraying, increasingly put pressure on malaria control measures. $^{33}$ However, the susceptibility of vulnerable populations with no or altered immunity to infection, such as young children and pregnant women, is an important factor as well. ${ }^{34-39}$ Epidemics can arise in the case of extreme climate events including floods associated with extreme rainfall events, in such nonexposed population, that is, naive population. ${ }^{21,40,41}$ The inconsistency between drought conditions and increased malaria transmission during the 
1970s encouraged scientists to monitor and study the evolution of mosquito vectors in Senegal. ${ }^{42}$ Several studies conclude that the large malaria transmission observed during the Sahel drought was related to an increased number of vulnerable individuals and increased drug resistance of certain malaria vectors. ${ }^{43-45}$

Access to long time series of clinical malaria data covering a large geographical domain, for example, for the whole of West Africa, is very difficult. Climate reanalysis provides a unique opportunity to investigate the evolution of global climate variables along time. Reanalysis data can be used to drive malaria models with the aim of obtaining longer time series of simulated malaria parameters, over a continuous spatial grid. Previous studies have used reanalysis data to drive mathematical malaria models and investigate the variability of malaria parameters at regional and national scales. ${ }^{46}$ For example, simulated malaria incidence driven by daily weather station data were validated against malaria clinical data obtained from medical centers in Senegal. ${ }^{47,48}$ In this study, we now extend the methodology to the whole West African region, to explore seasonal and long-term trends in simulated malaria burden. Malaria model outputs are also compared with recent observation datasets from Senegal for validation purposes.

\section{DATA AND METHODS}

Our area of study, West Africa, is shown in Figure 1.

The Liverpool Malaria Model (LLM). The LMM is a dynamical malaria model driven by daily time series of rainfall and temperature.

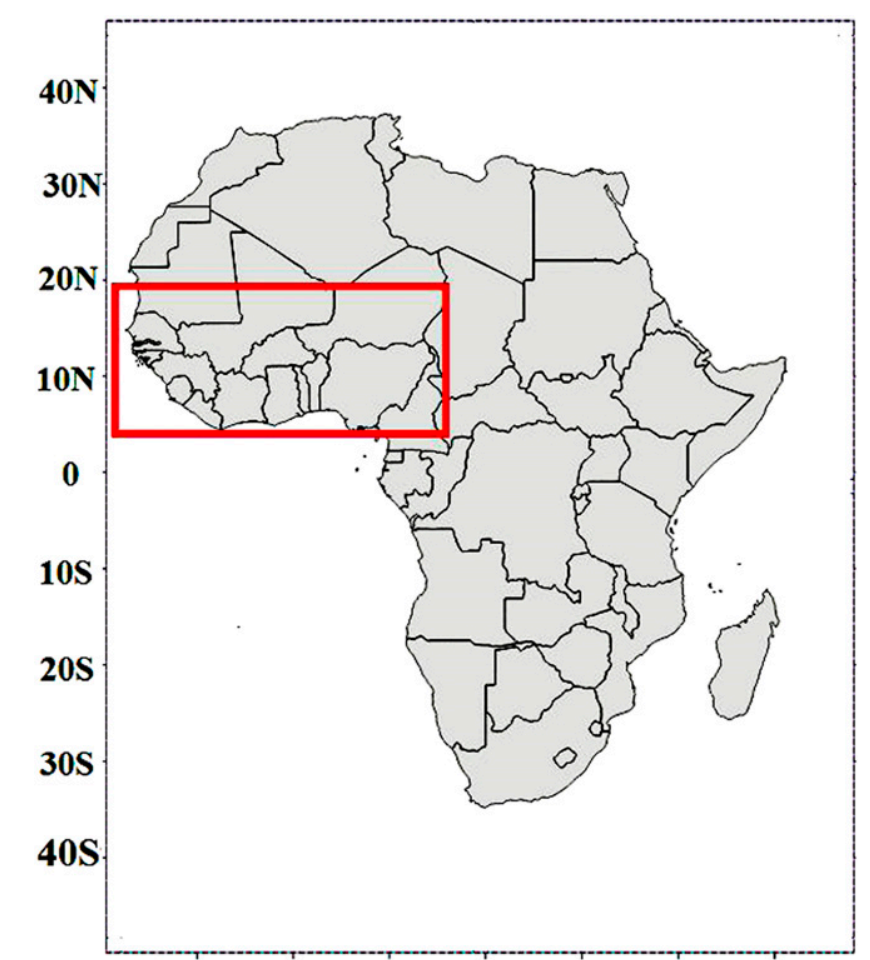

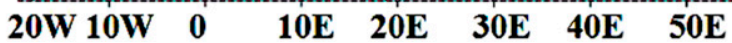

Figure 1. Location of the study area: West Africa $\left(4^{\circ} \mathrm{N}-18^{\circ} \mathrm{N}\right.$ and $\left.20^{\circ} \mathrm{W}-15^{\circ} \mathrm{E}\right)$ delineated in red. This figure appears in color at www.ajtmh.org.
The various components of the malaria transmission model and the model parameter settings are described by Hoshen and Morse. ${ }^{49}$ The LMM is a mathematicalbiological model of parasite dynamics, which comprises the weather-dependent within-vector stages and the weatherindependent within-host stages. The mosquito population is simulated using larval and adult stages, with the number of eggs deposited into breeding sites and the larval mortality rate depending on the previous 10 days' rainfall. The adult mosquito mortality rate and the egg-laying/biting cycle (the so-called gonotrophic cycle) also depend on temperature. The process of parasite transmission between humans and mosquitoes is modeled with temperature dependencies for the replication rate of the parasite within the mosquito (sporogonic cycle) and the mosquito biting rate. Both cycles evolve as a function of the number of "degree days" above a specific temperature threshold. The gonotrophic and the sporogonic cycles take, respectively, 37 and 111 degree days with thresholds of $9^{\circ} \mathrm{C}$ and $18^{\circ} \mathrm{C} .{ }^{50}$ The model does not simulate host immunity. The LMM is very sensitive to the climate data inputs and the disease model parameterization. Studies on climate and health have used LMM simulations in southern Africa, including Zimbabwe, Botswana, and for the whole African continent. ${ }^{47,51}$ The LMM version 2010 is used in this study. ${ }^{52}$ The malaria model outputs include incidence which is used in this study; it is defined by the number of infected cases in 100 people.

Surveillance malaria data for Senegal. The data used for validation over Senegal are recorded by the Programme National de Lutte contre le Paludisme (PNLP, the national malaria control program in Senegal), and all age-groups were screened. ${ }^{6}$ The number of observed malaria cases is available for various health districts in Senegal for the period 2001-2010. These malaria data are recorded and averaged from 11 main sites (Dakar, Diourbel, Fatick, Kaolack, Kolda, Louga, Matam, Saint-Louis, Tambacounda, Thies, and Ziguinchor) for all health districts and hospitals to derive monthly time series. The selection of these sentinel sites provides a good representation of malaria transmission in different climatic zones of Senegal. These cases are clinically confirmed using rapid diagnostic tests, ${ }^{53}$ as recommended by the WHO.

Climate dataset. Reanalysis climate datasets are used to drive the LMM. Reanalysis is a systematic approach to produce data sets for climate monitoring and research. Reanalyses are created using a fixed data assimilation scheme and climate model(s), which assimilate all available observations. This framework provides a dynamically consistent estimate of the climate state at each time step. The component of this framework, which varies, is the source of the raw input observation data. This is unavoidable because of the everchanging earth observational network which includes, but is not limited to, radiosonde, satellite, buoy, aircraft, and ship reports. Presently, approximately 7-9 million observations globally are assimilated at each time step for the production of reanalysis products. Reanalysis products have proven to be quite useful when used with appropriate care.

For comparison, four different reanalysis datasets are used in this study. The Twentieth Century Reanalysis was used for the period $1910-2009$ at $2.5^{\circ} \times 2.5^{\circ}$ spatial resolution, ${ }^{54}$ and the National Center for Environmental Prediction (NCEP) Reanalysis ${ }^{55}$ was used for the period 1948-2017 at $2.5^{\circ} \times 2.5^{\circ}$ spatial resolution. These two 
reanalysis datasets are provided by the National Oceanic Atmospheric Administration. The European Centre for Medium-Range Weather Forecasts (ECMWF) Atmospheric Reanalysis of the Twentieth Century (ERA20C) reanalysis dataset is available from 1910 to 2010 at $2.5^{\circ} \times 2.5^{\circ}$ spatial resolution, ${ }^{56}$ and the interim ECMWF Re-Analysis (ERAInterim) data, for the period $1979-2017$, at $1.5^{\circ} \times 1.5^{\circ}$ spatial resolution. $^{57}$ These two reanalysis datasets are available from the ECMWF.

Model validation and scores. For rainfall, July-AugustSeptember (JAS) and, for temperature, September-OctoberNovember (SON) are considered. The annual cycle is estimated from datasets by taking the average of monthly values for all years, and the interannual variability is calculated from datasets by taking the annual mean, that is, the average of all months for a given year. Climatologically, the seasonal cycle is commonly estimated from datasets by taking the average of all the months during the considered season. We have calculated correlations between the different simulated malaria incidence indices and observed malaria cases. After removing the seasonal cycle first, standardized anomaly values were correlated. Standardized anomalies are defined as the difference between seasonal incidence and the climatological average; this difference is then divided by the standard deviation of the seasonal incidence. A standard Pearson's $R$ test was then used to estimate the statistical significance of correlations coefficients. All results were significant at the $99 \%$ confidence interval $(\mathrm{Cl})$.

\section{RESULTS}

Spatial, seasonal, and interannual variability of rainfall and temperature in West Africa. Figure 2 represents the average of rainfall during JAS (Figure 2A-D) and temperature during SON (Figure 2E-H) for the different reanalysis datasets, respectively (20CR, NCEP, ERA20C, and ERA-Interim). The wettest area is located over the southern part of West Africa (Figure 2A-D). Rainfall ranges between $50 \mathrm{~mm} / \mathrm{month}$ in the northern part to $400 \mathrm{~mm} / \mathrm{month}$ in the southern part of West Africa. Compared with other reanalysis datasets, the rainfall amount per month is lower for ERA20C ( 50 to $100 \mathrm{~mm} /$ month, except for the Gulf of Guinea). This difference in rainfall amounts (Figure 2) can be attributed to biases in rainfall
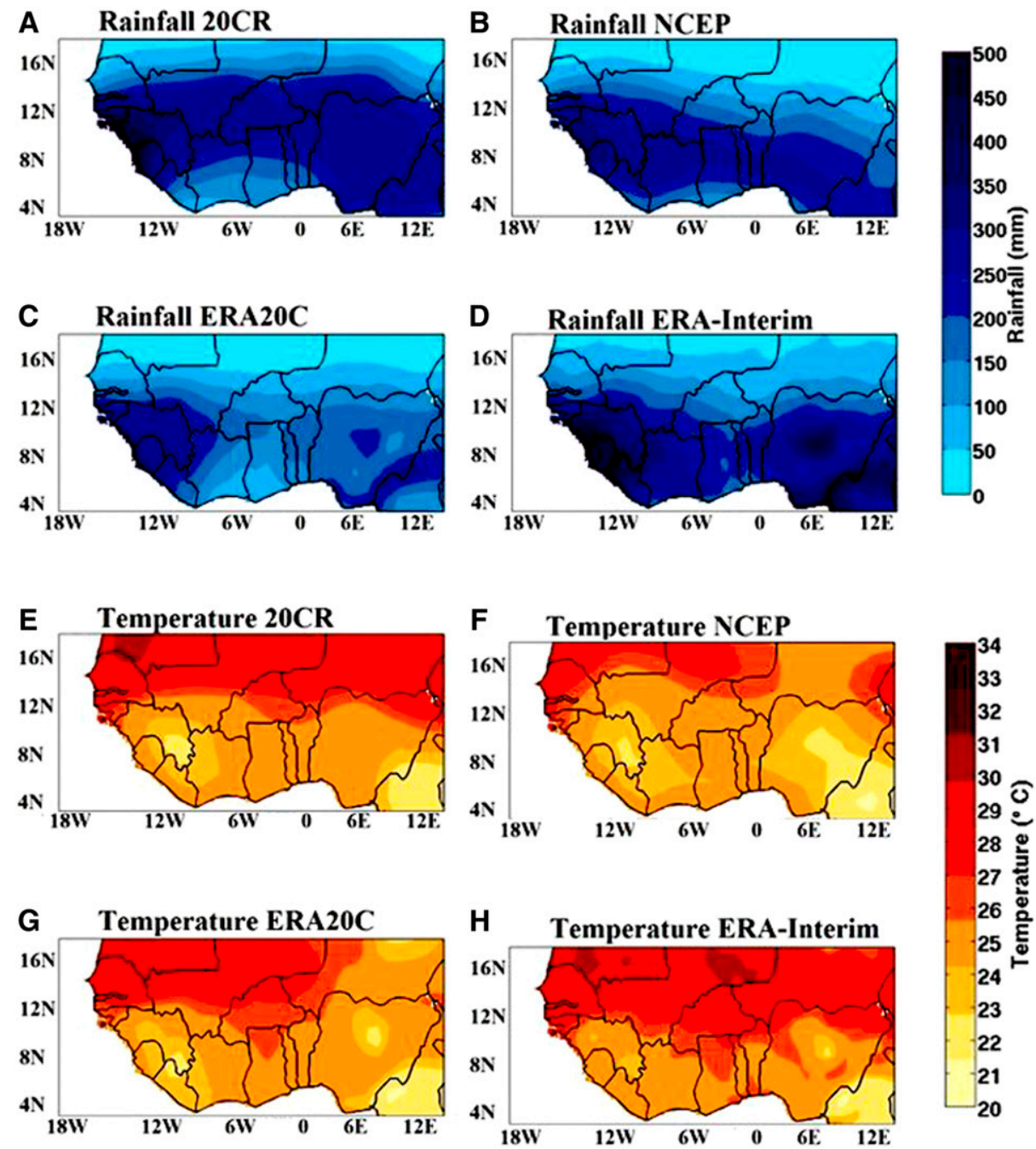

FIGURE 2. (A-D) Average July-August-September rainfall and (E and F) September-October-November temperature for the different reanalysis datasets, respectively (20CR, National Center for Environmental Prediction [NCEP], European Centre for Medium-Range Weather Forecasts Atmospheric Reanalysis of the Twentieth Century [ERA20C], and interim ECMWF Re-Analysis [ERA-Interim]). This figure appears in color at www.ajtmh.org. 
products provided by the 20CR, NCEP, ERA20C, and ERAInterim reanalysis datasets.

The warmest areas are located over the northern part of West Africa, bordering the Sahara desert (Figure 2E-H). Temperatures averaged over West Africa generally show a bimodal evolution, with peaks in April-May and October.

Seasonality in rainfall and temperature for the different reanalysis datasets is shown in Figure 3. Figure 3A-D shows the rainfall season ( $y$ axis), with a maximum during the boreal summer (JAS). Regarding the interannual variability ( $x$ axis), the signal is less comparable between reanalysis data and illustrates that West Africa experienced several erratic rainfall regimes during the common period (1979-2009). Significant multi-decadal rainfall variability is also shown. This finding is coherent with the Atlantic Multi-decadal Oscillation and changes in vegetation cover over the Sahel. ${ }^{58,59}$ Warm temperatures are well represented in all
$A_{\text {Dec }}$ Rainfall 20CR

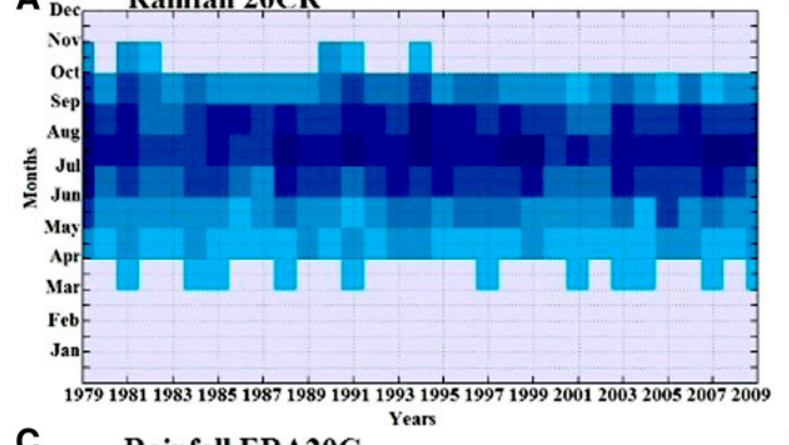

C

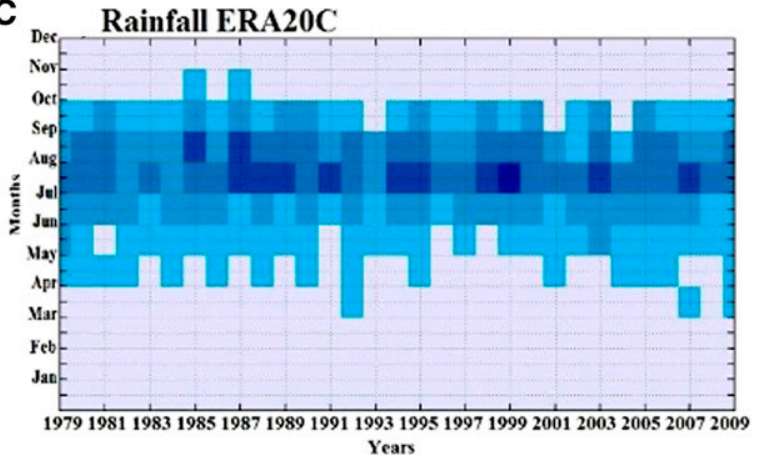

E

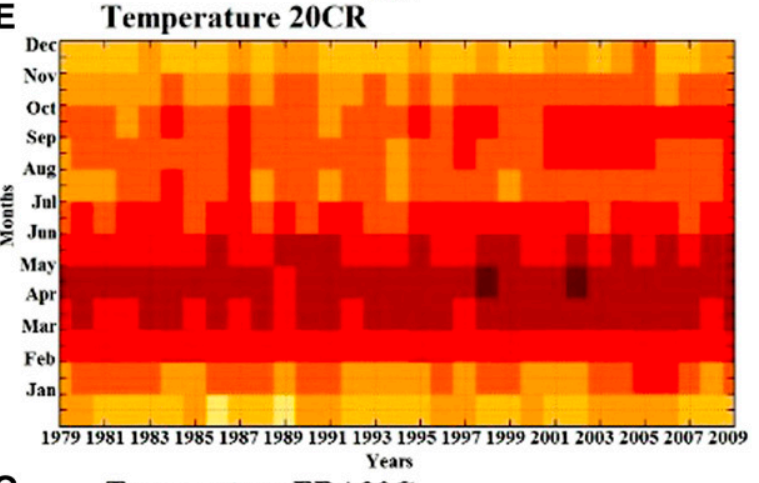

G

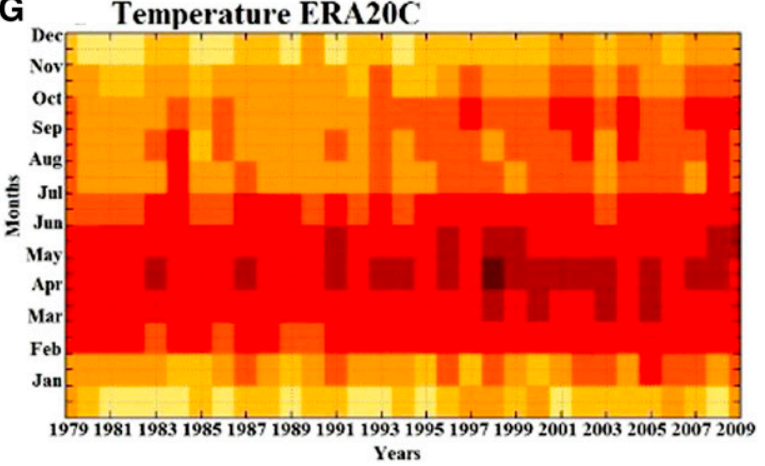

B

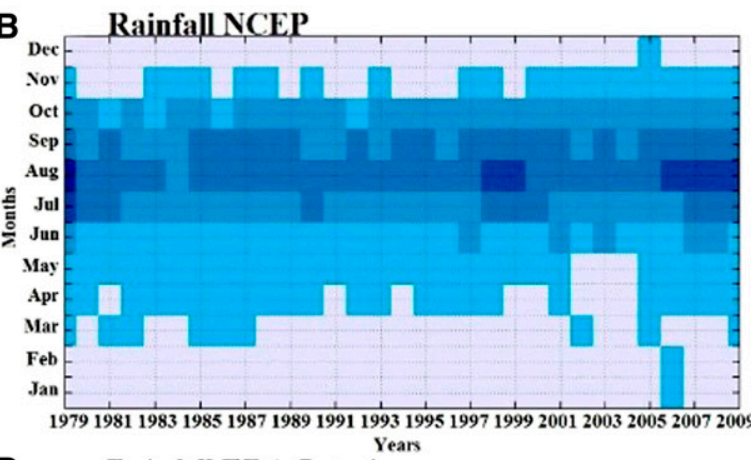

D

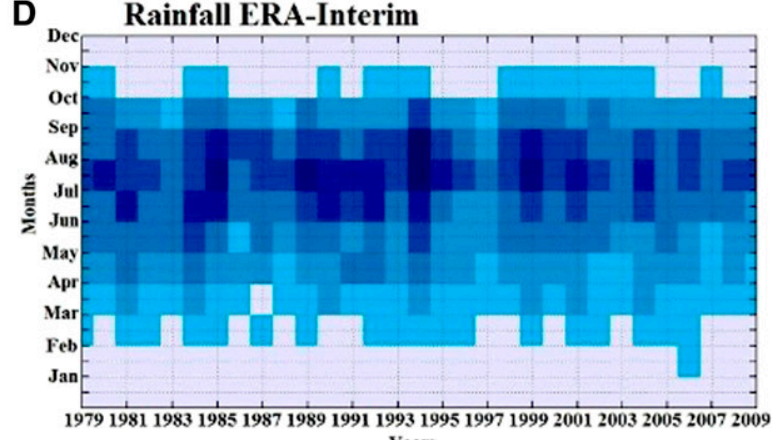

Rainfall ERA-Interim

F

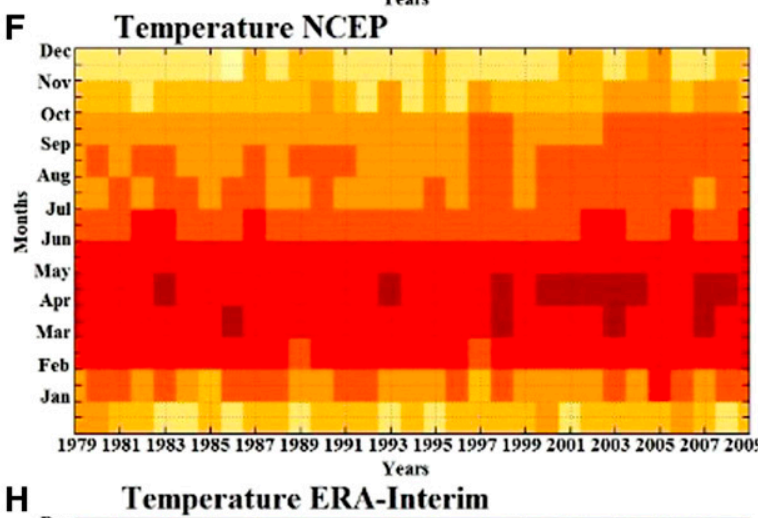

H

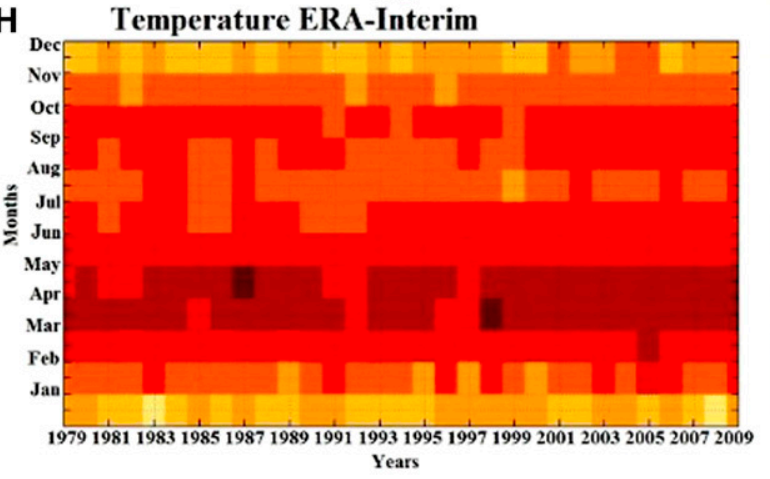

FIGURE 3. Intra-annual/interannual variability of climate parameters in West Africa. (A-D) Rainfall for the different reanalysis products (20CR, National Center for Environmental Prediction [NCEP], European Centre for Medium-Range Weather Forecasts Atmospheric Reanalysis of the Twentieth Century [ERA20C], and interim ECMWF Re-Analysis [ERA-Interim]). (E-H) Temperature for the same datasets. This figure appears in color at www.ajtmh.org. 
reanalysis products, showing a realistic seasonal cycle (with warmest temperatures in March-June) and a significant increasing trend during the recent period (Figure 3E-H).

Validation of seasonal and interannual cycles of simulated malaria incidence over Senegal. Annual simulated malaria incidence (\%) and observed malaria cases are overlaid onto the annual cycle of rainfall and temperature for Senegal in Figure 4. The simulated malaria season in Senegal, in particular, takes place between September and November, with a clear peak in October; this is confirmed also by the observed malaria cases (Figure 4). Malaria transmission takes place toward the end of the rainy season in Senegal, following heavy and frequent monsoon rains occurring between July and October (Figure 4, blue line). Temperature seasonality presents a bimodal evolution with two peaks, one in May and the other in October (Figure 4, black line). Figure 5 shows malaria incidence interannual variability, based on LMM malaria simulations driven by the 20CR, NCEP, ERA20C, and ERA-Interim reanalysis datasets (Figure $5 \mathrm{~A}$ and $\mathrm{B}$ ) and observed malaria data by the PNLP (Figure 5E). Simulated incidence values are largest from September to November on average, for all simulations (Figure 5A-D). This finding is consistent with seasonality in the observed number of cases (Figure $5 E$ ). If we focus on long-term reanalysis data (20CR and ERA20C), there is a decrease in simulated malaria incidence during the drought (1970s-1980s), with respect to the wet period (1950s-1960s). Some differences can be noticed between the different reanalysis-driven simulations. Figure 6 represents the standardized malaria indices over Senegal. The long time series (20CR and ERA20C) are showing very similar trends. A tendency toward a decrease in simulated malaria incidence and observed malaria cases is depicted during the most recent years. A peak in malaria cases is observed in 2010; this feature is also shown for the simulated indices (NCEP and ERA-Interim). Low malaria in 2001/2002 might be related to drier-than-average conditions in Senegal. Large correlation coefficients are found between simulated malaria incidence and observed number of malaria cases in Senegal (Table 1). The best correlation coefficients are obtained with NCEP and ERA-Interim ( $r=0.93$ and $r=0.95$, respectively). The correlation is slightly lower for ERA20C than for other reanalysis datasets.
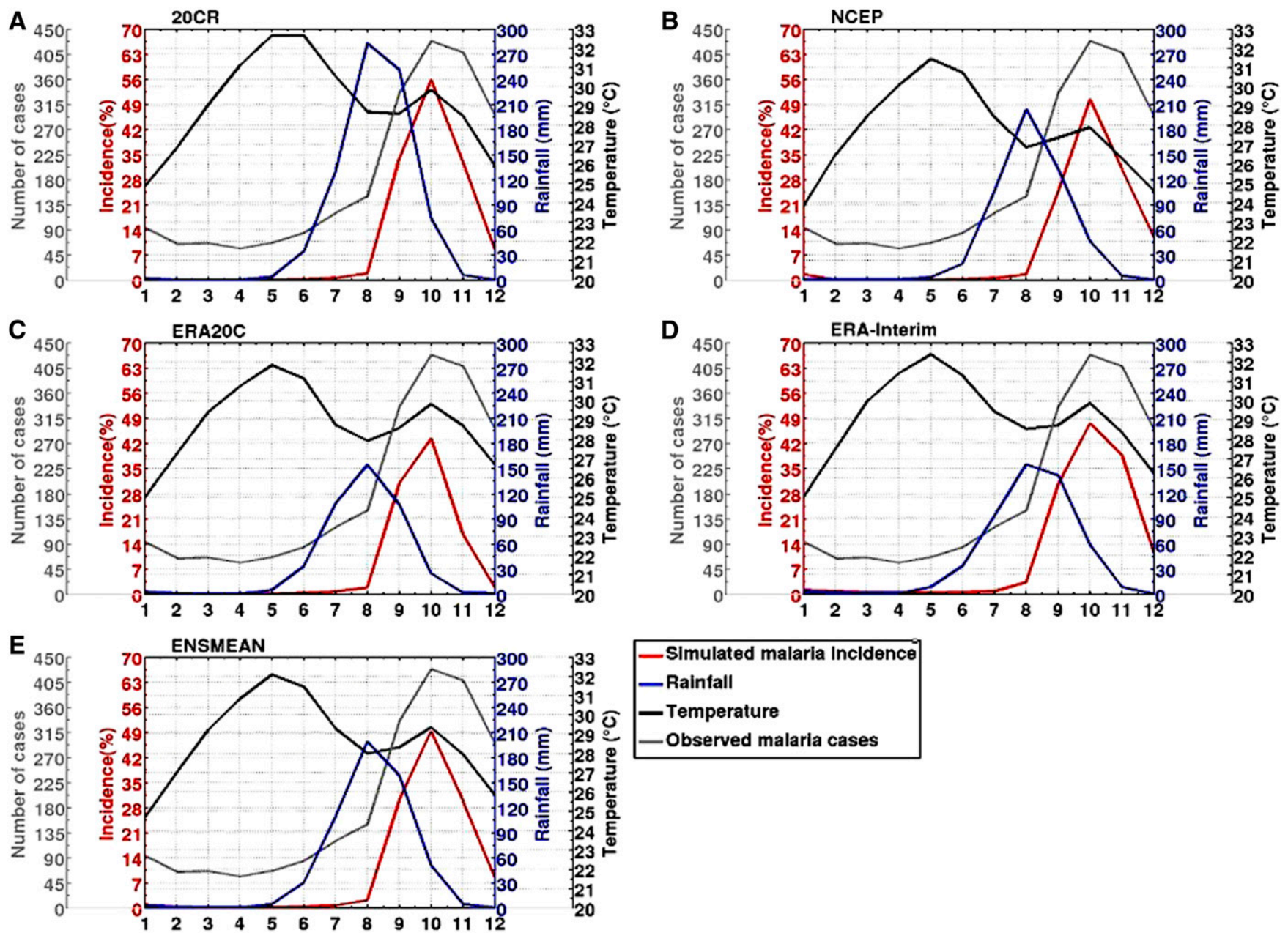

Figure 4. Annual cycle of climate input parameters (rainfall in $\mathrm{mm}$, blue line; temperature in ${ }^{\circ} \mathrm{C}$, black line) based on reanalysis data, simulated malaria incidence (\%, red line), and observed malaria cases in Senegal (gray line) for (A) 20CR, (B) National Center for Environmental Prediction (NCEP), (C) European Centre for Medium-Range Weather Forecasts Atmospheric Reanalysis of the Twentieth Century (ERA20C), (D) interim ECMWF Re-Analysis (ERA-Interim), and (E) the ensemble mean (ENSMEAN) of all reanalysis data for the common period 2001-2009. This figure appears in color at www.ajtmh.org. 

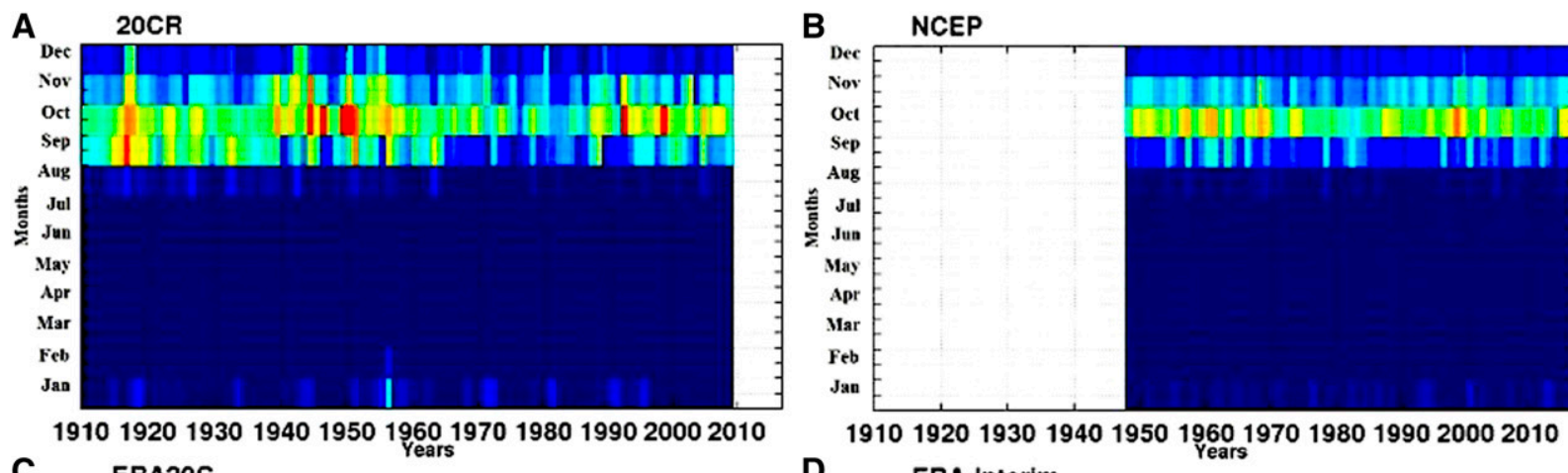

19101920193019401950196019701980199020002010
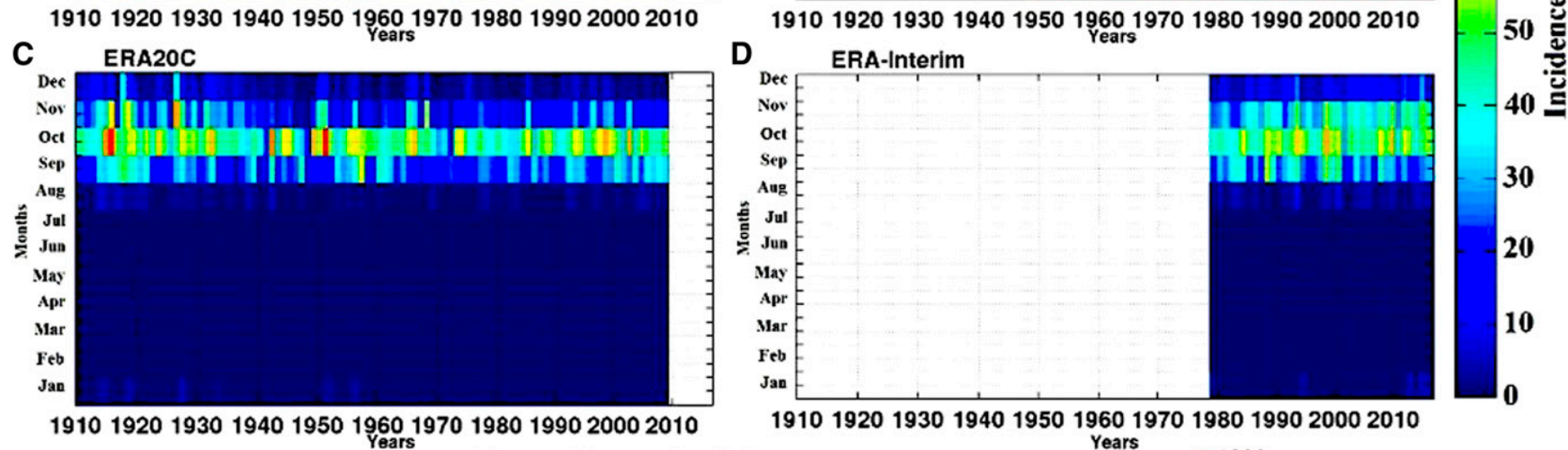

19101920193019401950196019701980199020002010

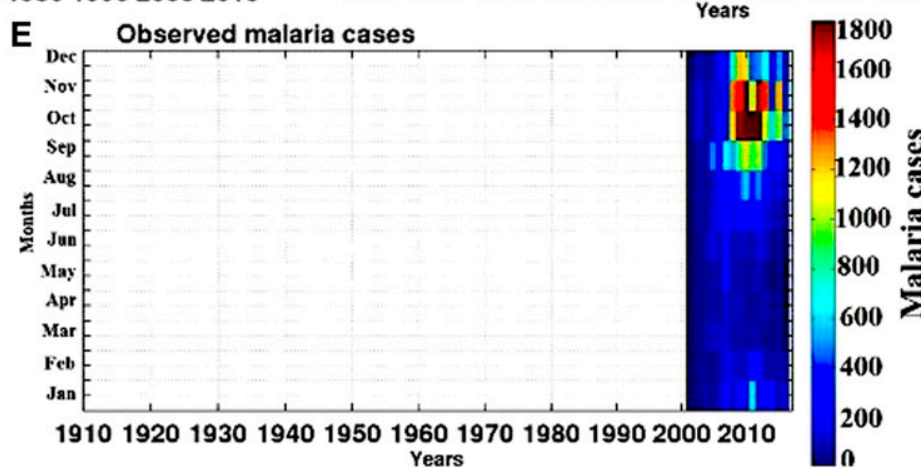

FIGURE 5. Intra-annual/interannual variability of malaria incidence (\%) in Senegal, for the different reanalysis products. (A) 20CR, (B) National Center for Environmental Prediction (NCEP), (C) European Centre for Medium-Range Weather Forecasts Atmospheric Reanalysis of the Twentieth Century (ERA20C), (D) interim ECMWF Re-Analysis (ERA-Interim), and (E) observed malaria cases over Senegal. The different datasets are scaled to the same time period (1910-2017). Missing data appear as white. This figure appears in color at www.ajtmh.org.

Seasonal, interannual, and spatial variability of simulated malaria incidence in West Africa. The seasonal cycle of simulated malaria incidence is predominantly unimodal over West Africa (Figure 7). For the simulated malaria incidence, the season SON is considered. High malaria transmission is simulated in SON, corresponding to two months after the peak of rains (in August) and to the second seasonal peak in temperature (October). This finding is consistent across the different reanalysis products and the ensemble mean over the common period, that is, 1979-2009 (Figure 7). The spatial distribution of simulated malaria incidence is shown in Figure 8, for all reanalysis dataset. Simulated malaria incidence follows a meridional gradient coinciding with gradients in temperature and rainfall. The largest incidence (greater than 60\%) is simulated over the southern part of West Africa, whereas incidence in the northern part is very low (about 0-5\%). The annual and interannual variability of simulated malaria incidence (\%) is shown in Figure 9. The simulated malaria season usually occurs between September and November, with a clear peak in October. Malaria transmission takes place toward the end of the rainy season in West Africa, following both heavy and frequent monsoon rains. Transmission generally continues until the beginning of the dry season during unusual wet years depending on the duration of the temporary ponds.

With regard to long-term changes, the simulated malaria incidence (20CR and ERA20C) seems to follow the three main rainfall phases in the Sahel: 1 ) an important signal in malaria transmission until the late 1960s, 2) a period with a weak malaria incidence consistent with the 1970s-1980s drought, and 3 ) a recovery period with high malaria transmission from the late 1990s up to today. The simulated decrease in malaria incidence during the drought is more pronounced for the NCEP simulations (Figure 9B). The decrease in simulated incidence during the 1970s-1980s drought is consistent with an observed decrease in vector abundance (in particular, Anopheles funestus) as reported by field studies. ${ }^{60}$

\section{DISCUSSION}

Climate variability has a significant impact on the agropastoral productivity and natural ecosystems, but it also 


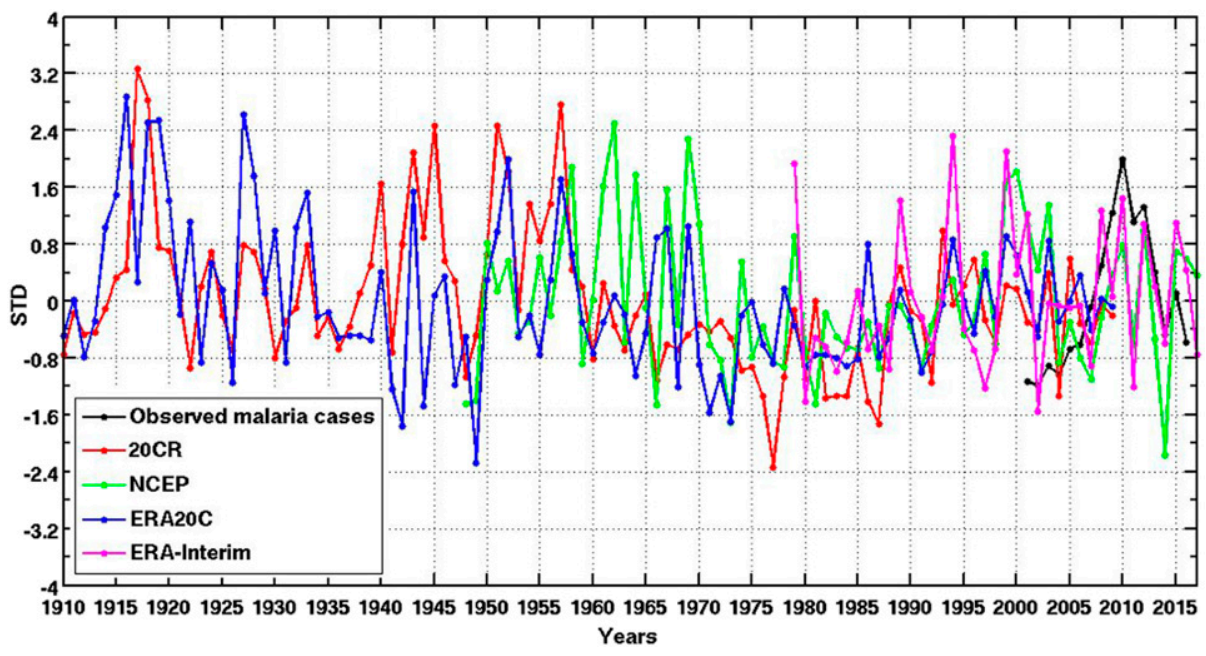

FIGURE 6. Standardized malaria indices (observation vs. simulations) over Senegal, periods are scaled to the same time period (e.g., 1910-2017). This figure appears in color at www.ajtmh.org.

affects the distribution of vector-borne diseases. Long-term trends in rainfall are related to anthropogenic factors, whereas decadal variability is associated with natural variability climatic modes such as the Atlantic Multi-decadal Oscillation. Interannual variability is related to natural modes of variability such as the El Niño Southern Oscillation, Atlantic Niños, Mediterranean sea surface temperature variability, and internal climate variability. ${ }^{61-65}$ Large malaria incidence can be related to suitable local climate and environmental conditions allowing for the proliferation of mosquitoes. Malaria outbreaks are usually caused by 1) the loss of immunity in vulnerable population after several years without malaria infection and 2) environmental and/or suitable conditions. As an illustration, the cessation of malaria control activities during the late 1970s, combined with heavy rainfall related to El Niño 1997-1998, led to a large malaria epidemic in Uganda. ${ }^{41}$ Warm temperatures over the northern part of West Africa can also lead to high malaria incidence if particular wet conditions occur some years.

Our results highlighted a significant relationship among seasonal malaria and seasonal rainfall and also temperature. Malaria incidence was shown to be related to seasonal rainfall with a lag of about 2 months; the rainfall season peaked in JAS, and the peak of the malaria transmission season then occurred in SON. This result was consistent with previous studies using surveillance malaria data for Senegal. ${ }^{47,48}$ For Mali, ${ }^{66}$ there were similar peaks in malaria cases from
September to November and a 3-month lag following the rainy season peak, which is also noted for Niger. ${ }^{67}$ Similar studies were carried out by other authors for Senegal, ${ }^{68-70}$ but none used climate parameters and a malaria model to generate potential malaria parameters in Senegal and extend the study to the West African domain; neither study used different available reanalysis datasets to drive a mathematical malaria model. The seasonal cycle and variability of the input climate variables present some differences across reanalysis datasets, a feature that directly affects the seasonal cycle and variability of simulated malaria model outputs. The most important difference was shown for the magnitude of the malaria transmission peak. Because LMM is very sensitive to rainfall input data, these differences in simulated malaria incidence are likely related to large rainfall changes between the wet (1950-1969) and the dry period (1970-1990). However, the different simulations agreed that malaria transmission was constrained by climate parameters (rainfall and temperature) approximately following the latitudinal rainfall gradient in West Africa. There was a consistent 1- to 2-month lag between the peak of the rainy season and the simulated peak in malaria incidence across all reanalysis datasets; this finding was consistent with observations in Senegal and other West African countries. In reality, the observed malaria prevalence rate was very low in Senegal, which is likely attributable to the positive effects of malaria control measures such as distribution of ITNs and artemisinin-based combination therapy for

Correlations coefficients between simulated malaria incidence and observed malaria cases based on the mean seasonal cycle

\begin{tabular}{l} 
Driving climate data \\
\hline $20 \mathrm{CR}$ \\
National Center for Environmental \\
Prediction \\
European Centre for Medium-Range \\
Weather Forecasts (ECMWF) \\
Atmospherved number of malaria cases in Senegal
\end{tabular}

All values are significant at the $99 \% \mathrm{Cl}$. 

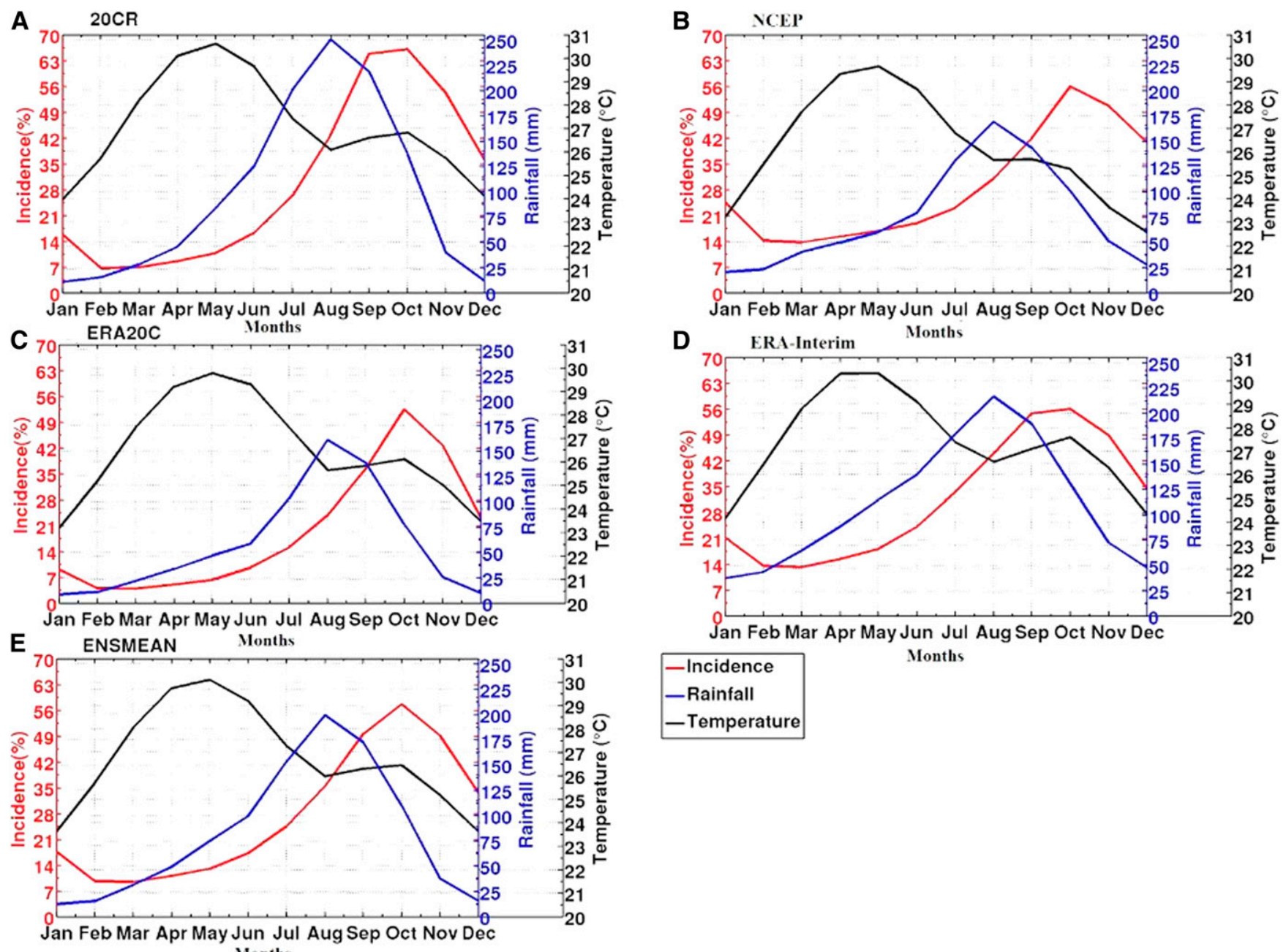

FiguRE 7. Annual cycle of climate input parameters (rainfall in $\mathrm{mm}$ and temperature in ${ }^{\circ} \mathrm{C}$ ) based on different reanalysis datasets and simulated malaria incidence (\%) in West Africa for (A) 20CR, (B) National Center for Environmental Prediction (NCEP), (C) European Centre for Medium-Range Weather Forecasts Atmospheric Reanalysis of the Twentieth Century (ERA20C), (D) interim ECMWF Re-Analysis (ERA-Interim), and (E) the ensemble mean of all reanalysis data for the common period (1979-2009). This figure appears in color at www.ajtmh.org.

treatment. In general, the northern part of Senegal experienced unstable malaria transmission; this is mainly related to unsuitable climate conditions. The southern part of Senegal where wetter conditions were located showed higher malaria prevalence. Significant reductions in malaria transmission was achieved over the last 15 years, with elimination occurring in a small number of countries ${ }^{71}$; however, increasing drug and insecticide resistance threatens these recent gains. Recent studies analyzed patterns of variation and covariation in resistance to these insecticides, using statistical methods that handle the sparse spatiotemporal distribution of available clinical data. ${ }^{72,73}$ They found a relationship between the different insecticide types that are consistent across large parts of Africa, allowing the prediction of resistance to be improved by incorporating observations. These factors related to resistance or intervention measures were not included in the LMM calibration, but they can somehow explain discrepancies between real malaria cases and simulated malaria incidence by the model.

In this article, we found that high malaria transmission took place from September to November corresponding to the second peak of the annual cycle of temperature and two months after the peak of the heavy rains in August. In addition, the spatial distribution of malaria was characterized. Observed malaria data and simulated malaria outputs were consistent and allow the validation of simulations performed with reanalysis data sets over Senegal. The LMM showed good agreement with the observed Senegal data. The study was extended using the products from different reanalyses to drive the malaria model for West Africa, but validation in other parts of West Africa is still needed. Longer term changes and reliability of reanalyses as driving conditions for the malaria model were investigated.

These findings are useful for achieving the main goal of this study, which was to validate the LMM over Senegal to extend the information on malaria parameters to the whole West African region and for a longer period. These results can be useful for stakeholders to develop mitigation and vector control strategies. Our results highlighted that the southern part of Senegal was most at risk of malaria epidemics, where control program efforts have to be conducted to make the best use of available resources. This study improved our knowledge about climate variability and malaria in Senegal and encourages validation in other parts of West Africa. 

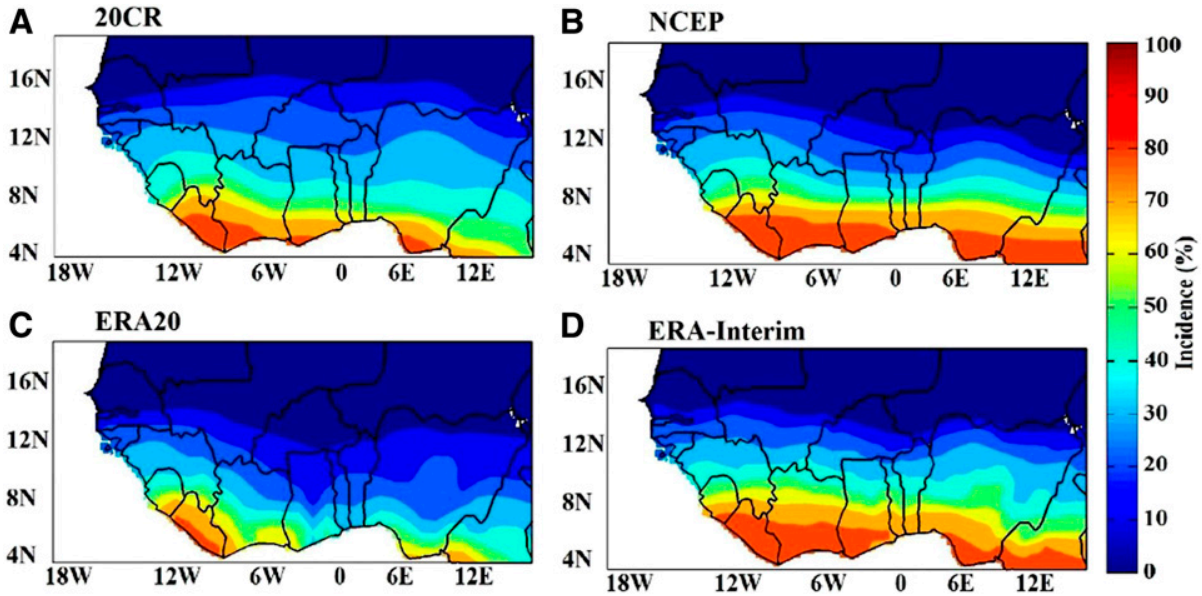

FIGURE 8. Annual mean malaria incidence (\%) for the common period 1979-2009 in West Africa, for the different reanalysis products. (A) 20CR, (B) National Center for Environmental Prediction (NCEP), (C) European Centre for Medium-Range Weather Forecasts Atmospheric Reanalysis of the Twentieth Century (ERA20C), and (D) interim ECMWF Re-Analysis (ERA-Interim). This figure appears in color at www.ajtmh.org.

Received January 21, 2019. Accepted for publication February 1, 2020.

Published online March 16, 2020.

Acknowledgments: We thank this program, whose scholarship awarded to I. D. permits the achievement of this study. We would also like to thank the Department of Meteorology, Faculty of Physics, at the Universidad Complutense de Madrid (UCM), who welcomed I. D. and partly supported special issues, mainly during his stay in July 2014 within the framework of the cooperation project VR 63/12 between LPAOSF-UCAD (Dakar) and UCM (Madrid), and also within the framework of the XII Convocatoria UCM de Cooperación al Desarrollo and the I-COOP Project ICOOP-202024B. The QWeCl Project funded by the European Commission Seventh Framework Research Programme under the grant agreement 243964 is also greatly acknowledged.

Financial support: This study was funded by the Erasmus Mundus Action 2 Strand 1 Lot-15 (ACP) program. The research was partly funded by the National Institute for Health Research Health Protection Research Unit (NIHR HPRU) in Emerging and Zoonotic Infections at the University of Liverpool in partnership with Public Health England (PHE) and Liverpool School of Tropical Medicine (LSTM). This work was partially funded by NOAA as part of a Service Level Agreement between NWS and CPO.

Disclaimer: The views expressed are those of the author(s) and not necessarily those of the NHS, the NIHR, and the Department of Health or Public Health England.

Disclosure: A. P. M. reports personal fees from ANR French Funding Agency outside the submitted work.

Authors' addresses: Ibrahima Diouf, NOAA Center for Weather and Climate Prediction, University Research Court, College Park, MD, and Laboratoire de Physique de l'Atmosphère et de l'Océan-Siméon Fongang, Ecole Supérieure Polytechnique de l'Université Cheikh Anta Diop, Dakar, Sénégal, E-mail: ibrahima.diouf@noaa.gov. Belén Rodriguez Fonseca, Department of Geophysics and Meteorology, Universidad Complutense de Madrid, Madrid, Spain, and Instituto de Geociencias IGEO, CSIC-UCM, Agencia Estatal del Consejo Superior de Investigaciones Científicas, Spain, E-mail: brfonsec@fis.ucm.es. Cyril Caminade, Department of Epidemiology and Population Health,
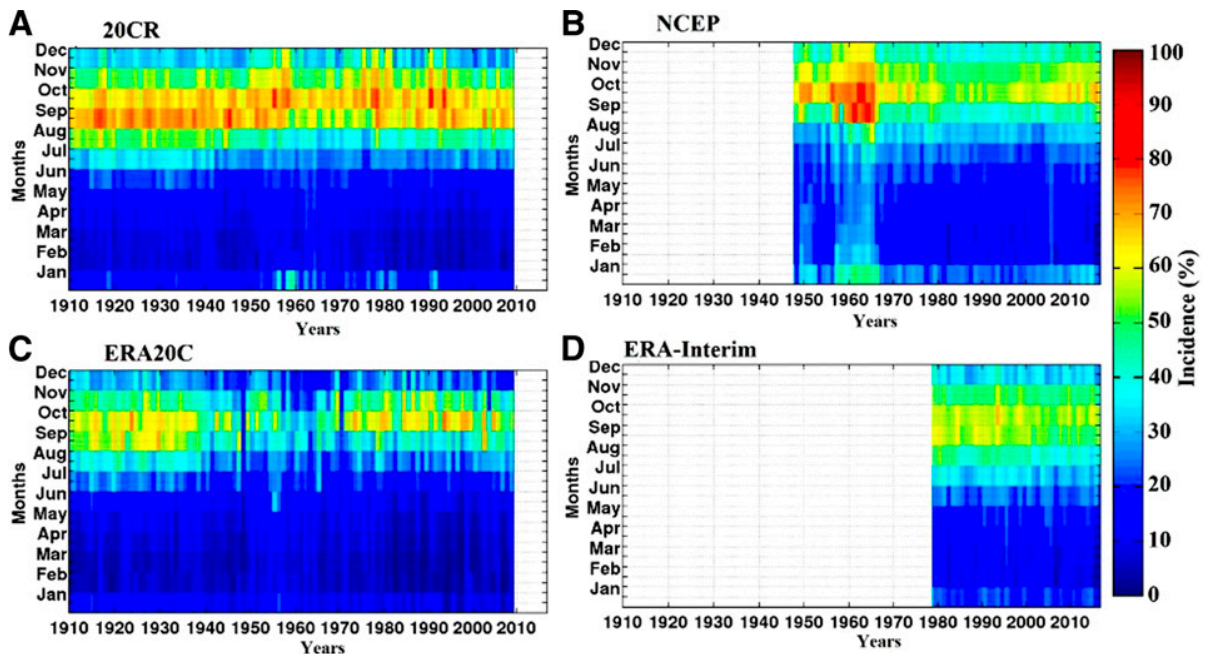

FIGURE 9. Intra-annual/interannual variability of simulated malaria incidence (\%) in West Africa, for the different reanalysis products. (A) 20CR, (B) National Center for Environmental Prediction (NCEP), (C) European Centre for Medium-Range Weather Forecasts Atmospheric Reanalysis of the Twentieth Century (ERA20C), and (D) interim ECMWF Re-Analysis (ERA-Interim). Periods are scaled to the same time period (e.g., 1910-2009). Missing values appear as white. The largest values in simulated malaria incidence are shown in the 20CR experiment. This figure appears in color at www.ajtmh.org. 
Institute of Infection and Global Health, University of Liverpool, Liverpool, United Kingdom, and National Institute for Health Research [M1] (NIHR), Health Protection Research Unit in Emerging and Zoonotic Infections, Liverpool, United Kingdom, E-mail: cyril.caminade@ liverpool.ac.uk. Wassila M. Thiaw, NOAA Center for Weather and Climate Prediction, College Park, MD, E-mail: wassila.thiaw@ noaa.gov. Abdoulaye Deme, Unité de Formation et de Recherche de Sciences Appliquées et de Technologie, Université Gaston Berger, Saint-Louis, Sénégal, E-mail: abdoulaye.deme@ugb.edu.sn. Andrew P. Morse, National Institute for Health Research [M1] (NIHR), Health Protection Research Unit in Emerging and Zoonotic Infections, Liverpool, United Kingdom, and Department of Geography and Planning, School of Environmental Sciences, University of Liverpool, Liverpool, United Kingdom, E-mail: a.p.morse@liverpool.ac.uk. Jacques-André Ndione, Centre de Suivi Écologique, Dakar, Sénégal, E-mail: jacandre.ndione@ansts.sn. Amadou Thierno Gaye, Laboratoire de Physique de l'Atmosphère et de l'Océan-Siméon Fongang, Ecole Supérieure Polytechnique de I'Université Cheikh Anta Diop, DakarFann, Dakar, Sénégal, E-mail: atgaye@ucad.edu.sn. Anta Diaw and Marie Khemesse Ngom Ndiaye, General Direction of Public Health, Ministry of Health and Social Action, Dakar, Senegal, E-mails: docanta70@gmail.com and ndiayekhemesse@yahoo.fr.

\section{REFERENCES}

1. World Health Organization, 2003. The Africa Malaria Report 2003. Available at: https://endmalaria.org/resources/library?type $=1$. Accessed December 1, 2014.

2. Robert V, Macintyre K, Keating J, Trape JF, Duchemin JB, Warren $\mathrm{M}$, Beier JC, 2003. Malaria transmission in urban sub-Saharan Africa. Am J Trop Med Hyg 68: 169-176.

3. Sachs J, Malaney P, 2002. The economic and social burden of malaria. Nature 415: 680-685.

4. Worrall E, Rietveld A, Delacollette C, 2004. The burden of malaria epidemics and cost-effectiveness of interventions in epidemic situations in Africa. Am J Trop Med Hyg 71: 136-140.

5. WHO, 2017. World Malaria Report, 2017. Geneva, Switzerland: WHO. Licence: CC BY-NC-SA 3.0 IGO.

6. Programme Nationale de Lutte Contre le Paludisme, 2009. Situation de la Lutte Contre le Paludisme au Sénégal. Enquête Nationale sur le Paludisme au Sénégal Entre 2008 et 2009 (ENPS-II). Calverto, MD: ICF Macro [in French].

7. Deuxième Communication Nationale du Sénégal sur Changements Climatiques, 2010. Vulnérabilité du Secteur de la Santé. Available at: http://unfccc.int/resource/docs/natc/sennc2.pdf. Accessed February 18, 2020.

8. Gething PW, Smith DL, Patil AP, Tatem AJ, Snow RW, Hay SI, 2010. Climate change and the global malaria recession. Nature 465: 342.

9. Tanser FC, Sharp und BD, le Sueur, 2003. Potential effect of climate change on malaria transmission in Africa. Lancet 362: 1792-1798.

10. Besancenot JP, Ndione JA, Handschumacher P, Ibrahima M, Laaidi K, 2004. Climat, eau et santé au Sahel ouest-Africain. Sci Chang Planétaires Sécher 15: 233-241.

11. Folland CK, Owen JA, Ward MN, Colman AW, 1991. Prediction of seasonal rainfall in the Sahel region of Africa using empirical and dynamical methods. J Forecast 10: 21-56.

12. Freeman T, Bradley M, 1996. Temperature is predictive of severe malaria years in Zimbabwe. Trans $R$ Soc Trop Med Hyg 90: 232.

13. Akhtar R, McMichael AJ, 1996. Rainfall and malaria outbreaks in western Rajasthan. Lancet 348: 1457-1458.

14. Briët OJ, Vounatsou P, Gunawardena DM, Galappaththy GN, Amerasinghe $\mathrm{PH}, 2008$. Temporal correlation between malaria and rainfall in Sri Lanka. Malar J 7: 77.

15. Galardo AKR, Zimmerman RH, Lounibos LP, Young LJ, Galardo CD, Arruda M, D'Almeida Couto AAR, 2009. Seasonal abundance of anopheline mosquitoes and their association with rainfall and malaria along the Matapi River, Amapi, Brazil. Med Vet Entomol 23: 335-349.

16. Hawking F, Wilson ME, Gammage K, 1971. Evidence for cyclic development and short-lived maturity in the gametocytes of Plasmodium falciparum. Trans $R$ Soc Trop Med Hyg, 65: 549-555.
17. Bayoh MN, 2001. Studies on the Development and Survival of Anopheles gambiae Sensu Stricto at Various Temperatures and Relative Humidities. PhD Thesis, University of Durham.

18. Yamana TK, Eltahir EA, 2013. Incorporating the effects of humidity in a mechanistic model of Anopheles gambiae mosquito population dynamics in the Sahel region of Africa. Parasit Vectors 6: 235.

19. McKenzie FE, Killeen GF, Beier JC, Bossert WH, 2001. Seasonality, parasite diversity, and local extinctions in Plasmodium falciparum malaria. Ecology 82: 2673-2681.

20. Krefis AC, Schwarz NG, Krüger A, Fobil J, Nkrumah B, Acquah S, May J, 2011. Modeling the relationship between precipitation and malaria incidence in children from a holoendemic area in Ghana. Am J Trop Med Hyg 84: 285-291.

21. Boyce R, Reyes R, Matte M, Ntaro M, Mulogo E, Metlay JP, Siedner MJ, 2016. Severe flooding and malaria transmission in the western Ugandan highlands: implications for disease control in an era of global climate change. $J$ Infect Dis 214: 1403-1410.

22. Paaijmans KP, Wandago MO, Githeko AK, Takken W, 2007. Unexpected high losses of Anopheles gambiae larvae due to rainfall. PLoS One 2: e1146.

23. Lemasson JJ, Fontenille D, Lochouarn L, Dia I, Simard F, 1997. Comparison of behavior and vector efficiency of Anopheles gambiae and Anopheles arabiensis (Diptera: Culicidae) in Barkedji, a Sahelian area of Senegal. J Med Entomol 34: 396-403.

24. Robert V, Planchon O, Lapetite JM, Esteves M, 1999. Rainfall is not a direct mortality factor for anopheline larvae. Parasite 6: 195-196.

25. Muriu SM, Muturi EJ, Shililu JI, Mbogo CM, Mwangangi JM, Jacob BG, Irungu LW, Mukabana RW, Githure JI, Novak RJ, 2008. Host choice and multiple bloods feeding behavior of malaria vectors and other anophelines in Mwea rice scheme, Kenya. Malar J 7: 43.

26. Diatta M, Spiegel A, Lochouarn L, Fontenille D, 1998. Similar feeding preferences of Anopheles gambiae and $A$. arabiensis in Senegal. Trans R Soc Trop Med Hyg 92: 270-272.

27. Caminade C, Kovats S, Rocklov J, Tompkins AM, Morse AP, Colón-González FJ, Lloyd SJ, 2014. Impact of climate change on global malaria distribution. Proc Natl Acad Sci USA 111: 3286-3291.

28. Dai A, Lamb PJ, Trenberth KE, Hulme M, Jones PD, Xie P, 2004. The recent Sahel drought is real. Int J Climatol 24: 1323-1331.

29. Held IM, Delworth TL, Lu J, Findell KL, Knutson TR, 2005. Simulation of Sahel drought in the 20th and 21st centuries. Proc Natl Acad Sci USA 102: 17891-17911.

30. Lebel T, Ali A, 2009. Recent trends in the central and western Sahel rainfall regime 1990-2007. J Hydrol 375: 1-2.

31. Faye O, Diallo S, Gaye O, Faye O, Mouchet J, 1992. Évaluation de l'efficacité du fénitrothion (Sumithion ${ }^{\circledR}$ PM40) sur la densité du vecteur et la prévalence du paludisme à Pout (Thiès, Sénégal). Ann Soc Belge Med Trop 72: 103-112.

32. Faye O, Gaye O, Hervé JP, Diack PA, Diallo S, 1993. Le paludisme en zone sahélienne du Sénégal. 2. Indices parasitaires. Ann Soc Belge Med Trop 73: 31-36.

33. Trape JF, Pison G, Preziosi MP, Enel C, Desgrées du Loû A, Delaunay V, Samb B, Lagarde E, Molez JF, Simondon F, 1998. Impact of chloroquine resistance on malaria mortality. CRAcad Sci III 321: 689-697.

34. Snow RW et al., 1997. Relation between severe malaria morbidity in children and level of Plasmodium falciparum transmission in Africa. Lancet 349: 1650-1654.

35. Ter Kuile FO, Parise ME, Verhoeff FH, Udhayakumar V, Newman RD, Van Eijk AM, Steketee RW, 2004. The burden of coinfection with human immunodeficiency virus type 1 and malaria in pregnant women in sub-Saharan Africa. Am J Trop Med Hyg 71: 41-54.

36. Wagner G, Koram K, Mcguinness D, Bennett S, Nkrumah F, Riley $E, 1998$. High incidence of asymptomatic malara infections in a birth cohort of children less than one year of age in Ghana, detected by multicopy gene polymerase chain reaction. $A m \mathrm{~J}$ Trop Med Hyg 59: 115-123.

37. McGregor IA, 1987. Malarial immunity: current trends and prospects. Ann Trop Med Parasitol 81: 647-656. 
38. Snow RW, Nahlen B, Palmer A, Donnelly CA, Gupta S, Marsh K, 1998. Risk of severe malaria among African infants: direct evidence of clinical protection during early infancy. $J$ Infect Dis 177: 819-822.

39. Trape JF, Zante EL, Legros F, Druilhe $\mathrm{P}$, Rogier $\mathrm{C}$, Bouganali $\mathrm{H}$, Salem G, 1993. Malaria morbidity among children exposed to low seasonal transmission in Dakar, Senegal and its implications for malaria control in tropical Africa. Am J Trop Med Hyg 48: 748-756.

40. Haines A, Kovats RS, Campbell-Lendrum D, Corvalán C, 2006. Climate change and human health: impacts, vulnerability and public health. Public Health 120: 585-596.

41. Kilian AHD, Langi P, Talisuna A, Kabagambe G, 1999. Rainfall pattern, El Niño and malaria in Uganda. Trans $R$ Soc Trop Med Hyg 93: 22-23.

42. Verruysse J, Jancloes M, 1981. Etude entomologique du paludisme humain dans la zone urbaine de Pikine (Sénégal). Cah. ORSTOM, Sér Ent Méd Parasitol 19: 165-178.

43. Lochouarn L, Dia I, Coluzzi M, Faye O, Robert V, Simard F, Lemasson JJ, Fontenille D, 1996. Les vecteurs du paludisme au Sénégal: une systématique en évolution. Dakar Médical: Bulletin de la Société Médicale d'Afrique Noire de Langue Française Spécial, 55-58p.

44. Ndiaye F, Molez JF, Trape JF, 1998. Endémie palustre. Delaunay V, ed. La Situation Démographique et Épidémiologique Dans la Zone de Niakhar au Senegal: 1984-1996. Dakar, Senegal: Orstom, 118-122.

45. White NJ, 2004. Antimalarial drug resistance. J Clin Invest 113: 1084-1092.

46. Jones EA, Morse AP, 2010. Application and validation of a seasonal ensemble prediction system using a dynamic malaria model. J Clim 23: 4202-4215.

47. Diouf I, Deme A, Ndione JA, Gaye AT, Rodriguez FB, Cisse M, 2013. Climate and health: observation and modeling of malaria in the Ferlo (Senegal). Comptes Rendus Biol 336: 253-260.

48. Diouf I, Rodriguez-Fonseca B, Deme A, Caminade C, Morse AP, Cisse M, Gaye AT, 2017. Comparison of malaria simulations driven by meteorological observations and reanalysis products in Senegal. Int J Environ Res Public Health 14: 1119.

49. Hoshen MB, Morse AP, 2004. A weather-driven model of malaria transmission. Malar J 3: 32.

50. Caminade $\mathrm{C}$ et al., 2011. Mapping Rift Valley fever and malaria risk over West Africa using climatic indicators. Atmos Sci Lett 12: 96-103.

51. Morse AP, Doblas-Reyes FJ, Hoshen MB, Hagedorn R, Palmer TN, 2005. A forecast quality assessment of an end-to-end probabilistic multi-model seasonal forecast system using a malaria model. Tellus 57: 464-475.

52. Ermert V, Fink AH, Jones AE, Morse AP, 2011. Development of a new version of the Liverpool Malaria Model. I. Refining the parameter settings and mathematical formulation of basic processes based on a literature review. Malar J 10: 35 .

53. Moody A, 2002. Rapid diagnostic tests for malaria parasites. Clin Microbiol Rev 15: 66-78.

54. Compo GP et al., 2011. The twentieth century reanalysis project. Q J R Meteorol Soc 137: 1-28.

55. Kalnay E, Kanamitsu M, Kistler R, Collins W, Deaven D, Gandin L, Joseph D, 1996. The NCEP/NCAR 40-year reanalysis project. Bull Am Meteorol Soc 77: 437-471.

56. Poli $P$ et al., 2016. ERA-20C: an atmospheric reanalysis of the twentieth century. J Clim 29: 4083-4097.
57. Dee DP et al., 2011. The ERA-Interim reanalysis: configuration and performance of the data assimilation system. Quart $J$ Roy Meteor Soc 137: 553-597.

58. Rodríguez-Fonseca B et al., 2015. Variability and predictability of West African droughts: a review on the role of sea surface temperature anomalies. J Clim 28: 4034-4060.

59. Zheng X, Eltahir EA, 1998. The role of vegetation in the dynamics of West African monsoons. J Clim 11: 2078-2096.

60. Mouchet J, Faye O, Julvez J, Manguin S, 1996. Drought and malaria retreat in the Sahel, West Africa. Lancet 348: 1735-1736.

61. Mohino E, Janicot S, Bader J, 2011. Sahel rainfall and decadal to multi-decadal sea surface temperature variability. Clim Dynam 37: 419-440.

62. Smith KR, Woodward A, Campbell-Lendrum D, Chadee D, Honda Y, Liu Q, Olwoch J, Revich B, Sauerborn R, 2014. Human health: impacts, adaptation, and co-benefits. Pages 709-754 in Climate Change 2014: Impacts, Adaptation, and Vulnerability. Part A: Global and Sectoral Aspects. Contribution of Working Group II to the Fifth Assessment Report of the Intergovernmental Panel on Climate Change. CB Field et al., eds. Cambridge and New York: Cambridge University Press.

63. Nicholson SE, Some B Kone B, 2000. An analysis on recent rainfall conditions in West Africa, including the rainy season of 1997 ENSO year. J Clim 13: 2628-2640.

64. Giannini A, Saravanan R, Chang P, 2003. Oceanic forcing of Sahel rainfall on interannual to interdecadal time scales. Science 302: 1027-1030.

65. Suárez-Moreno R, Rodríguez-Fonseca B, Barroso JA, Fink AH, 2018. Interdecadal changes in the leading ocean forcing of Sahelian rainfall interannual variability: atmospheric dynamics and role of multidecadal SST background. J Clim. 31: 6687-6710.

66. Coulibaly D, Travassos MA, Kone AK, Tolo Y, Laurens MB, Traore $\mathrm{K}$, Sissoko M, 2014. Stable malaria incidence despite scaling up control strategies in a malaria vaccine-testing site in Mali. Malar J 13: 374

67. Sissoko MS, Sissoko K, Kamate B, Samake Y, Goita S, Dabo A, Gaudart J, 2017. Temporal dynamic of malaria in a suburban area along the Niger River. Malar J 16: 420.

68. Faye O, Gaye O, Fontenille D, Hébrard G, Konate L, Sy N, Herve JP, Toure YT, Diallo S, Molez JF, 1995. Malaria decrease and drought in the Niayes area of northwestern Senegal. Cah Sante 5: 299-305.

69. Fontenille D, Lochouarn L, Diagne N, Sokhna C, Lemasson JJ, Diatta M, Konate L, Faye F, Rogier C, Trape JF, 1997. High annual and seasonal variations in malaria transmission by anophelines and vector species composition in Dielmo, a holoendemic area in Senegal. Am J Trop Med Hyg 56: 247-253.

70. Giardina F, Gosoniu L, Konate L, Diouf MB, Perry R, Gaye O, Faye $\mathrm{O}$, Vounatsou $\mathrm{P}, 2012$. Estimating the burden of malaria in Senegal: Bayesian zero-inflated binomial geostatistical modeling of the MIS 2008 data. PLoS ONE 7: e32625.

71. Mouchet J, Manguin S, Sircoulon J, Laventure S, Faye O, Onapa AW, Fontenille D, 1998. Evolution of malaria in Africa for the past 40 years: impact of climatic and human factors. $J$ Am Mosq Control Assoc 14: 121-130.

72. Coleman M, Hemingway J, Gleave KA, Wiebe A, Gething PW, Moyes CL, 2017. Developing global maps of insecticide resistance risk to improve vector control. Malar J 16: 86.

73. Hancock PA, Wiebe A, Gleave KA, Bhatt S, Cameron E, Trett A, Gething PW, 2018. Associated patterns of insecticide resistance in field populations of malaria vectors across Africa. Proc Natl Acad Sci USA 115: 5938-5943. 